\title{
Six1 induces protein synthesis signaling expression in duck myoblasts mainly via up-regulation of $m T O R$
}

\author{
Haohan Wang ${ }^{1}$, Xinxin $\mathrm{Li}^{1}$, Hehe Liu ${ }^{1}$, Lingli Sun ${ }^{1}$, Rongping Zhang ${ }^{1}$, Liang $\mathrm{Li}^{1}$, Mincheng Wangding ${ }^{1}$ and \\ Jiwen Wang ${ }^{1}$ \\ ${ }^{1}$ Institute of Animal Genetics and Breedings, Sichuan Agricultural University, Ya'an, China
}

\begin{abstract}
As a critical transcription factor, Six1 plays an important role in the regulation of myogenesis and muscle development. However, little is known about its regulatory mechanism associated with muscular protein synthesis. The objective of this study was to investigate the effects of overexpression of Six 1 on the expression of key protein metabolism-related genes in duck myoblasts. Through an experimental model where duck myoblasts were transfected with a pEGFP-duSix1 construct, we found that overexpression of duck Six 1 could enhance cell proliferation activity and increase mRNA expression levels of key genes involved in the PI3K/Akt/mTOR signaling pathway, while the expression of FOXO1, MuRF1 and MAFbx was not significantly altered, indicating that Six 1 could promote protein synthesis in myoblasts through up-regulating the expression of several related genes. Additionally, in duck myoblasts treated with LY294002 and rapamycin, the specific inhibitors of PI3K and mTOR, respectively, the overexpression of Six 1 could significantly ameliorate inhibitive effects of these inhibitors on protein synthesis. Especially, the mRNA expression levels of $m T O R$ and S6K1 were observed to undergo a visible change, and a significant increase in protein expression of S6K1 was seen. These data suggested that Six1 plays an important role in protein synthesis, which may be mainly due to activation of the mTOR signaling pathway.
\end{abstract}

Keywords: duck; Six 1; protein metabolism signaling; mTOR; pEGFP-duSix1.

Received: March 30, 2015; Accepted: August 24, 2015.

\section{Introduction}

Sixl(Sine oculis homeobox homolog 1), which belongs to the sine oculs homeobox gene family, plays extensive roles in regulating the development of many tissues and organs, especially the development of skeletal muscle (Fougerousse et al., 2002; Laclef et al., 2003; Brodbeck and Englert, 2004; Brugmann et al., 2004; Giordani et al., 2007). Indeed, absence of the Sixl gene caused mouse fetal death because of severe rib malformations and extensive muscle hypoplasia (Grifone et al., 2005). Furthermore, Yajima et al. (2010) showed that overexpression of Sixl in muscle satellite cells enhanced myoblast fusion and increased the number of nuclei per myotube. Intriguingly, myoblast fusion is a process similar to that occuring during muscle hypertrophy in adult skeletal muscle after overload (McCarthy et al., 2011). In addition, Kostek et al. (2007) detected that Six 1 expression significantly decreased after 3 and $6 \mathrm{~h}$ post resistance training of human leg muscle. Until now, although a lot of research about the roles of Sixl on skeletal muscle development and growth has been done,

Send correspondence to Jiwen Wang, College of Animal Science and Technology, Sichuan Agricultural University, 46 Xinkang Road, Ya'an, Sichuan Province, 625014, China. Email: wjw2886166@163.com. further studies on its regulatory mechanism involving muscle hypertrophy are still needed.

It is well known that skeletal muscle is high plastic in its organization, and its growth is known as a process of manifestation of externalization of muscle hypertrophy. This mainly depends on the ratio of muscular protein synthesis and degradation, and the size of muscular fiber increases when the rate of protein synthesis exceeds that of protein degradation. (Kimball, 2007; Tipton et al., 2009). Recent studies have showed that the PI3K/Akt/mTOR signaling axis, considered as one of the crucial signaling cascades, isinvolved in skeletal muscle hypertrophy (Dorn 2nd and Force 2005; Dorn 2nd 2007; Bernardo et al., 2010). Studies on swimming exercise-induced physiological hypertrophy in mouse heart revealed that Sixl was significantly up-regulated, and that Sixl and its cofactor Eya2 could directly up-regulate the expression of $m T O R$, hence indicating that the Six1-Eya2 complex is a key regulator of physiological hypertrophy (Lee et al., 2012). In addition, Sixl can not only stimulate the activation of Akt and MAPK, but it can also up-regulate the expression of p-Akt (Yu et al., 2006). Moreover, the promoter region of PI3K (p110 $\alpha$ ) contains putative Sixl binding sites. These studies indicated that Sixl plays a role in promoting muscle hyper- 
trophy. However, whether Six I can regulate protein synthesis to facilitate muscle growth is still unclear.

It is generally believed that activation of PI3K is induced by insulin-like growth factor I (IGF1) (Musaro et al., 2001). When IGF1 binds to IGF1 receptor it can result in insulin receptor substrate-1 phosphorylation, followed by activation of PI3K and production of phosphatidylinositol-3,4,5-triphosphates, which subsequently recruit Akt to the plasma membrane and phosphorylate Akt, finally leading to the activation of mTOR and blockade of glycogen synthase kinase $3 \beta$ (GSK3 $\beta$ ). Furthermore, mTOR activity is mediated by direct phosphorylation of its downstream targets S6K1 and PHAS-1, which can ultimately result in protein synthesis. In contrast, Akt stimulation can dominantly inhibit the induction of atrophy signaling. As genetic activation of Akt can phosphorylate FOXOs, the translocation and activity of FOXO transcription factors can upregulate the expression of Muscle Ring Finger1 (MuRF1) and Muscle Atrophy F-box (MAFbx), which encode E3 ubiquitin ligases, thus finally causing skeletal muscle protein degradation(Glass, 2005; Sandri, 2008). Protein synthesis and degradation in skeletal muscle being dependent on the changes in expression of PI3K/Akt/mTOR signaling pathways, it is of particular importance to study the regulatory mechanism between Six 1 and this signaling pathway.

In the present study aiming to investigate the effects of Six 1 on protein metabolism in duck myoblasts, we firstly determined the effects of overexpression of Sixl on the expression levels of key genes related to protein metabolism signaling pathway. Furthermore, in vitro cultured duck myoblasts were treated with LY294002 and rapamycin, specific inhibitors of PI3K and mTOR, respectively, and were subsequently transfected with a pEGFP-duSix 1 construct. Real-time RCR and western-blot methods were used to examine the expression levels of genes involved in the $\mathrm{PI} 3 \mathrm{~K} / \mathrm{Akt} / \mathrm{mTOR}$ signaling pathway. Our data showed that overexpression of Six 1 in myoblasts could significantly increase protein synthesis mainly via activation of the mTOR signaling pathway.

\section{Materials and Methods}

\section{Animals}

Hatching Peking duck (Anas platyrhynchos domestica) eggs were incubated at a temperature of $370.5^{\circ} \mathrm{C}$ and humidity of $86-87 \%$. Eight eggs were obtained randomly after 13 days of incubation from the Sichuan Agricultural University Waterfowl Breeding Experimental Farm. All procedures were approved by the Guidelines on Humane Treatment of Laboratory Animals (2006).

\section{Cell culture}

Primary myoblasts were isolated from the leg muscle of 13-day-old Peking duck embryos and purified using an improved technique of differential anchoring velocity and were seeded onto 6-well plates. The cells were cultured in Dulbecco's modified Eagle's medium-high glucose (DMEM) (Hyclone lab, Logan, UT), supplemented with $10 \%$ fetal bovine serum (FBS) (Gibco, New York) and kept at $37{ }^{\circ} \mathrm{C}$ in a humidified $5 \% \mathrm{CO}_{2}$ incubator. A trypsin $(0.25 \%)$ /EDTA solution was used to detach primary myoblasts from the culture plates for subculture (Continous cell culture).

\section{Cell treatments and transfection}

Duck myoblast cells were seeded into 6-well plates at a density of $110^{6}$ cell/plate and incubated in DMEM supplemented with $10 \% \mathrm{FBS}$ for $24 \mathrm{~h}$ at $37{ }^{\circ} \mathrm{C}$ in $5 \% \mathrm{CO}_{2}$ incubator. Cells were then treated with or without LY294002 (Beyotime, Shanghai, China) $(30 \mu \mathrm{M}$ and $40 \mu \mathrm{M})$, and after treating the cells for $12 \mathrm{~h}$ and $24 \mathrm{~h}$, respectively, these were washed twice with $1 \mathrm{~mL}$ of Hanks' balanced salt solution and harvested for subsequent real-time PCR and western-blotting analysis. The same method was used to treat cells with or without rapamycin (Beyotime, Shanghai, China) at 30nM and 40nM doses. Moreover, the cells were treated with LY294002 or rapamycin for proper time, followed by two washes with $1 \mathrm{~mL}$ of Hanks' balanced salt solution and then transfected with the duck recombinant pEGFP-duSix 1 vector (Wang et al., 2014) with or without $10 \mathrm{mmol} / \mathrm{l}$ 4-PBA for $24 \mathrm{~h}$ and $48 \mathrm{~h}$ using lipofectin 2000 (Invitrogen, USA) following the manufacturer's instructions. At the end of the incubation period, cells were harvested, and cell lysates were immediately frozen at $-80^{\circ} \mathrm{C}$ for subsequent analysis.

\section{MTT assay}

The MTT (3-(4,5-dimethylthiazol-2-yl)-2,5diphenyltetrazolium bromide) assay, which measures cell proliferation and cytotoxicity, was used to analyze myoblast proliferative activity. Subcultured myoblasts $(\sim 1000 /$ well $)$ were seeded into 96-wells plates and incubated for 12,24 or $48 \mathrm{~h}$ at $37^{\circ} \mathrm{C}$. MTT $(10 \mathrm{ul}, 5 \mathrm{mg} / \mathrm{ml}$, Sigma, China) was added into the culture system for $4 \mathrm{~h}$ at $37^{\circ} \mathrm{C}$. The solutions were then replaced with $150 \mathrm{ul}$ of dimethyl sulfoxide (DMSO, Sigma, China). After a $20 \mathrm{~min}$ incubation, the absorbance value of each well was measured using a microplate reader at a wave length of $570 \mathrm{~nm}$.

\section{Real-time PCR analysis}

Total RNA was extracted from cells using Trizol (Invitrogen, USA) following the manufacturer's instructions. RNA concentration and purity were determined by spectrophotometric absorbance at $260 \mathrm{~nm}$ and $280 \mathrm{~nm}$, and RNA integrity was detected by visualization of the $28 \mathrm{~S}$ and $18 \mathrm{~S}$ ribosomal subunits after electrophoresis in a $1.5 \%$ agarose gel. The SYBR Prime Script RT-PCR Kit (TaKaRa, Japan) was used for real-time PCR detection. Real-time PCR primers (Table 1) were designed for duck 
Table 1 - Primers used for quantitative real-time PCR used in this study.

\begin{tabular}{|c|c|c|c|c|}
\hline Gene name & Primer name & Primer sequence (5-3) & Product size (bp) & Annealing temperature $\left({ }^{\circ} \mathrm{C}\right)$ \\
\hline Sixl & $\begin{array}{l}\text { Q-Six1F } \\
\text { Q-Six1R }\end{array}$ & $\begin{array}{l}\text { GATGCTGCCGTCGTTTGG } \\
\text { AGGACGCTCTCGTTCTTGTG }\end{array}$ & 144 & 60 \\
\hline$P I 3 K$ & $\begin{array}{l}\text { Q-PI3KF } \\
\text { Q-PI3KR }\end{array}$ & $\begin{array}{l}\text { CTTTTACCGAGGAGGTTCTGTGG } \\
\text { CTGAAGGTTGGTCTTTGTGGAC }\end{array}$ & 137 & 60 \\
\hline$A k t$ & $\begin{array}{l}\text { Q- Akt F } \\
\text { Q- Akt R }\end{array}$ & $\begin{array}{l}\text { TCTTTGCTGGCATTGTTTGGC } \\
\text { GCTGTCATCTTGGTCAGGAGGAGT }\end{array}$ & 152 & 60 \\
\hline mTOR & $\begin{array}{l}\text { Q- mTOR F } \\
\text { Q- mTOR R }\end{array}$ & $\begin{array}{l}\text { CTATCTGCCTCAGCTCATTCCT } \\
\text { GTCATCCAGGTTAGCTCCAAAG }\end{array}$ & 121 & 60 \\
\hline$S 6 K 1$ & $\begin{array}{l}\text { Q- S6K1F } \\
\text { Q- S6K1R }\end{array}$ & $\begin{array}{l}\text { ATAATCGTGCTGTGGACTGGTG } \\
\text { TCTGGCTTCTTGTGTGAGGTAGG }\end{array}$ & 155 & 60 \\
\hline FOXO1 & $\begin{array}{l}\text { Q- FOXO1F } \\
\text { Q- FOXO1R }\end{array}$ & $\begin{array}{l}\text { AGGTTCACCAAATCCAGACTACAGG } \\
\text { CGTTGTGCGGAGGAGAATCAG }\end{array}$ & 182 & 60 \\
\hline$M A F b x$ & $\begin{array}{l}\text { Q- MAFbxF } \\
\text { Q- MAFbxR }\end{array}$ & $\begin{array}{l}\text { CAGACCCTCTACACATCCCTCT } \\
\text { GTTCAGTTGCTGTTGCCAGTG }\end{array}$ & 123 & 60 \\
\hline$M u R F 1$ & $\begin{array}{l}\text { Q- MuRF1F } \\
\text { Q- MuRF1R }\end{array}$ & $\begin{array}{l}\text { TCAACATCTACTGCGTCACCTG } \\
\text { GCTATTCAACTCGCTCTTCTGG }\end{array}$ & 128 & 60 \\
\hline$\beta$-actin & $\begin{array}{l}\text { Q- } \beta \text {-actinF } \\
\text { Q- } \beta \text {-actinR }\end{array}$ & $\begin{array}{l}\text { GCTATGTCGCCCTGGATTTC } \\
\text { CACAGGACTCCATACCCAAGAA }\end{array}$ & 168 & 60 \\
\hline$G A P D H$ & $\begin{array}{l}\text { Q-GAPDHF } \\
\text { Q-GAPDHR }\end{array}$ & $\begin{array}{l}\text { AAGGCTGAGAATGGGAAAC } \\
\text { TTCAGGGACTTGTCATACTTC }\end{array}$ & 254 & 60 \\
\hline
\end{tabular}

Sixl (GenBank Accession No: KC990828.1), PI3K, Akt, mTOR, S6K1, FOXO1, MAFbx, MuRF1 and for the detection of two reference genes, $\beta$-actin (GenBank Accession No: EF667345.1) and GAPDH (GenBank Accession No: GU564233.1). PCR assays were carried out with CFX96 real-Time PCR Detection System (Bio-Rad, CA, USA) in 96-well plates. Reactions mixtures of $25 \mu 1$ contained $1 \mu \mathrm{l}$ of cDNA template, $12.5 \mu \mathrm{l}$ of SYBR Premix Ex Taq, $10.5 \mu \mathrm{l}$ of sterile water, and $0.5 \mu \mathrm{l}$ of each gene specific primer (Table 1). The procedure for real-time PCR was as follows: $30 \mathrm{~s}$ of pre-denaturation reaction at $95^{\circ} \mathrm{C}$, followed by 40 cycles of $95^{\circ} \mathrm{C}$ for $10 \mathrm{~s}, 60^{\circ} \mathrm{C}$ for $40 \mathrm{~s}$ and $72^{\circ} \mathrm{C}$ for 20 $\mathrm{s}$, and finally a melting curve analysis program with 60 $95^{\circ} \mathrm{C}$ with a heating rate of $0.1^{\circ} \mathrm{C}$ per second and continuous fluorescence measurement. All PCRs were performed in triplicate for each sample, with tubes without cDNA as negative controls.

\section{Western-blotting}

Whole protein from cells of different treatments was exacted by disruption in RIPA buffer (Sigma-Aldrich, St. Louis, MO, USA) in the presence of protease inhibitor cocktail. The lysates were kept on ice for $1 \mathrm{~h}$, and then centrifuged at $12000 \mathrm{~g}$ for $20 \mathrm{~min}$ at $4^{\circ} \mathrm{C}$. The resulting supernatants were collected for western blot analysis. Protein concentrations were determined by the BCA protein assay (Beyotime, Shanghai, China) following the manufacturer's instructions. Approximately $15 \mu \mathrm{g}$ protein of each supernatant fraction was mixed with 6SDS sample buffer and boiled for $5 \mathrm{~min}$. Subsequently, the proteins were separated by $10 \%$ SDS-polyacrylamide gel electrophoresis (SDSPAGE), and then transferred to a PVDF membrane (MilliPore, Bedford, MA, USA). The membranes were blocked in 5\% non-fat dry milk in TBST ( 5 mmol Tris-HCl, pH 7.4, $136 \mathrm{mmol} \mathrm{NaCl}, 0.05 \%$ Tween 20 ) for $3 \mathrm{~h}$ at room temperature and then incubated with primary antibodies against FOXO1 (L27, Source:Rabbit), p-FOXO1 (Ser256, Source:Rabbit), S6K1(Source:Rabbit), and Tubulin at a 1:1000 dilution overnight at $4^{\circ} \mathrm{C}$. These antibodies were purchased from Cell Signaling Technology (Beverly, MA, USA). The next day, the membranes were washed three times for 15 min with TBST, followed by incubation in horse-radish peroxidase (HRP)-conjugated goat anti-IgG rabbit (dilution 1:500, Beyotime, Shanghai, China) for $3 \mathrm{~h}$ at room temperature and washed three times with TBST. Each sample was analyzed in triplicate. Antibody binding was detected by electro-chemiluminescence using fluorescence detection equipment (ChemiDoc XRS; Bio-Rad, Hercules, CA, USA).

\section{Statistical analysis}

The relative gene expression levels were analyzed and estimated using the comparative $\mathrm{Ct}\left(2^{-\Delta \Delta C t}\right)$ value method. Western-blot pixel densities between different treatment groups were analyzed by Student's $t$-test. All statistical analyses were performed using Microsoft Excel software and SAS version 9.13. Comparisons of the group means were run by one-way ANOVA and Duncan's multiple range test was used to analyze statistical significance. 
All results were shown as means \pm SEM. A P $<0.05$ was considered statistically significant.

\section{Results}

The influence of overexpression of duck Six1 on expression of key genes involved in the $\mathrm{PISK} / \mathrm{Akt} / \mathrm{mTOR}$ signaling pathway

Duck myoblasts were transfected with the eukaryotic expression vector $\mathrm{pEGFP-duSix} 1$. Figure $1 \mathrm{~A}$ shows that green fluorescence protein (GFP) was markedly expressed in Six1-transfected cells, indicating that Sixl was also expressed in duck myoblasts. Furthermore, results from the MTT assay showed that overexpression of Six 1 could stimulate cellular proliferation at $12 \mathrm{~h}$ and $24 \mathrm{~h}$ after transfection, exhibiting a significant increase in the absorption value at $570 \mathrm{~nm}$, and a higher cell proliferative activity at $24 \mathrm{~h}$ (Figure 1B).

Cells transfected with pEGFP-duSix 1 for $24 \mathrm{~h}$ and were harvested to detect both mRNA and protein levels of key genes related to protein synthesis and degradation. Results of real-time PCR showed that overexpression of duck Six 1 could influence both protein synthesis and degradation in myoblasts. Especially, mRNA expression levels of $m T O R$ and its downstream effector, $S 6 K 1$, which are central regulators of protein synthesis, were significantly increased $(\mathrm{P}<0.05)$ (Figure $1 \mathrm{C})$. The expression levels of $P I 3 K$ and $A k t$ mRNA displayed an increasing but not significant trend $(\mathrm{P}>0.05)$. Similar to PI3K and $A k t$, the mRNA expression levels of FOXO1, MuRF1 and MAFbx, which are related to protein degradation, were also not significantly changed $(\mathrm{P}>0.05)$. These results indicate that Sixl may play an important role in protein synthesis.

Similar to mRNA levels and protein phosphorylation status we observed no insignificant change in protein expression of FOXO1 after transfection. However, the protein expression of S6K1, which is a downstream effector of PI3K and mTOR required for positively regulating protein synthesis, was greatly increased by overexpression of Six 1 $(\mathrm{P}<0.05)$ (Figure 1D). All the results of real-time PCR and western-blot immunoassay are in supported that Sixl plays an important role in regulating protein synthesis.

The effect of overexpression of duck Six 1 on protein synthesis of myoblasts was blocked by LY294002

According to previous research, Six 1 may bind to the promoter region of PI3K ( $1110 \alpha)$, indicating that a potential regulatory relationship may exist between Six1 and PI3K signaling. To further elucidate whether Six 1 regulates the activation of PI3K signaling to affect protein synthesis, stable growth duck myoblasts were incubated in the presence or absence of LY294002, which is a highly potent and specific inhibitor of PI3K. In order to seek a proper time and concentration of LY294002 treatment, an MTT assay was used to test cell proliferative activity at $12 \mathrm{~h}$ and $24 \mathrm{~h}$ after treatment with $30 \mu \mathrm{M}$ and $40 \mu \mathrm{M}$ LY294002, respectively. As shown in Figure 2B, cell proliferative activity was significantly inhibited by LY294002. Moreover, the higher concentration showed more obvious inhibition of cell proliferation and more serious inhibitive effects at $24 \mathrm{~h}$ than at $12 \mathrm{~h}$ (Figure 2B). Subsequently, we transfected the LY294002- treated cells with pEGFP-duSix 1 for $24 \mathrm{~h}$ and $48 \mathrm{~h}$, respectively, and found that overexpression of duck Sixl could significantly increase cell proliferation activity after transfection (Figure 2B).

To verify our model of LY294002-treatment and to contextualize our expression results, relative expression levels of key genes were measured as previously experiment. Real-time PCR showed that PI3K expression was significantly reduced in the presence of LY294002 (Figure 2C), suggesting that LY294002 could significantly inhibit expression of PI3K. The lower PI3K activity was also associated with a decrease in expression levels of its downstream genes, including $A k t, m T O R, S 6 K 1$ which relate to protein synthesis, and FOXO1, MuRF1, MAFbx which are associated with protein degradation. Moreover, to determine whether overexpression of Sixl would improve the expression levels of these genes, the LY294002-treated cells were transfected with pEGFP-duSix 1 for $48 \mathrm{~h}$, as shown in Figure 2C. The expression of Sixl was notably increased $(\mathrm{P}<0.05)$, whereas $P I 3 K$ and $A k t$ were not changed $(\mathrm{P}>0.05)$. A similar trend in mRNA expression levels was also observed for $F O X O 1$ and its downstream targets $M u R F 1, M A F b x$. Contrary to the expression levels of PI3K and $A k t$, an increase in mRNA levels was seen for mTOR and $S 6 K 1$ in myoblasts, indicating that overexpression of Six 1 may up-regulate $m$ TOR expression to promote protein synthesis and ultimately to rescue the inhibitive effects of LY294002.

The expression levels of key proteins mentioned above were also examined by western-blot immunoassay, and the results revealed that the expression of key proteins was in accordance with mRNA levels, displaying a trend to reduced expression levels of FOXO1, p-FOXO1 and S6K1 protein after treatment with LY294002 in myoblasts. In contrast, after transfection with Six 1 for $48 \mathrm{~h}$, total FOXO1 protein levels were not changed, while its phosphorylation and S6K1 protein levels showed a great increase, suggesting that overexpression of Six 1 could promote activation of S6K1 and induce protein synthesis to rescue the inhibitive effects of LY294002.

\section{The effects of overexpression of duck Six 1 on protein synthesis of myoblasts were blocked by rapamycin}

From our previous experiments we saw that overexpression of Six 1 could increase expression levels of protein synthesis-related genes. Interestingly, in LY294002-treated cells which were transfected with pEGFP-duSix1, the mRNA expression of PI3K was not 

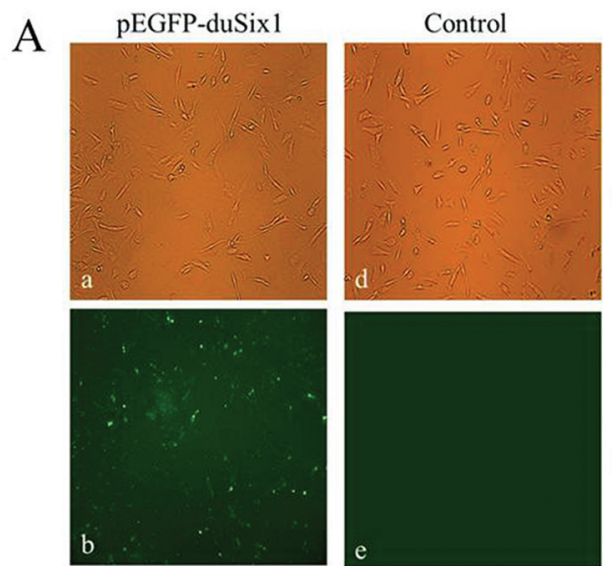

Cy3
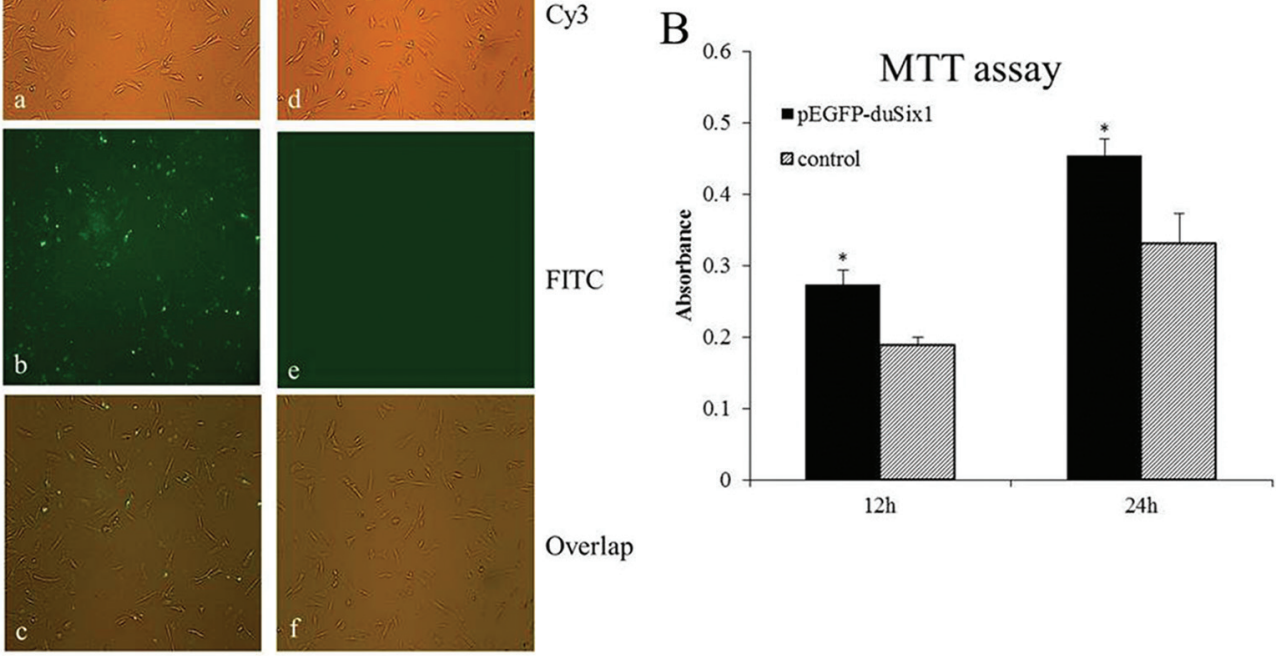

FITC

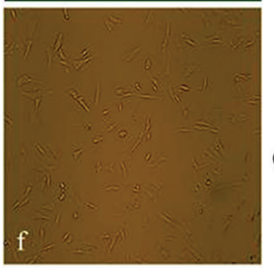

Overlap

C

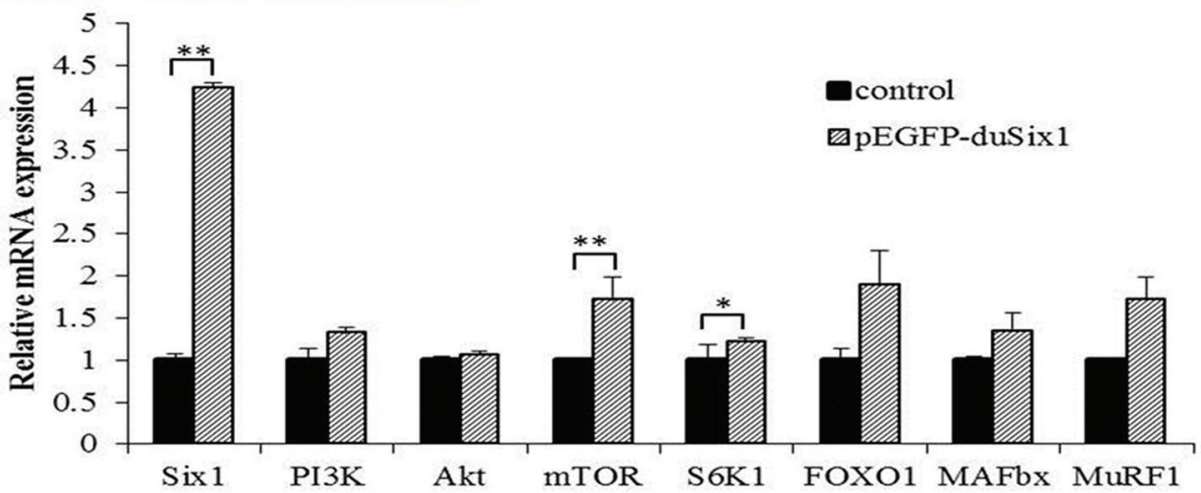

$\mathrm{D}$
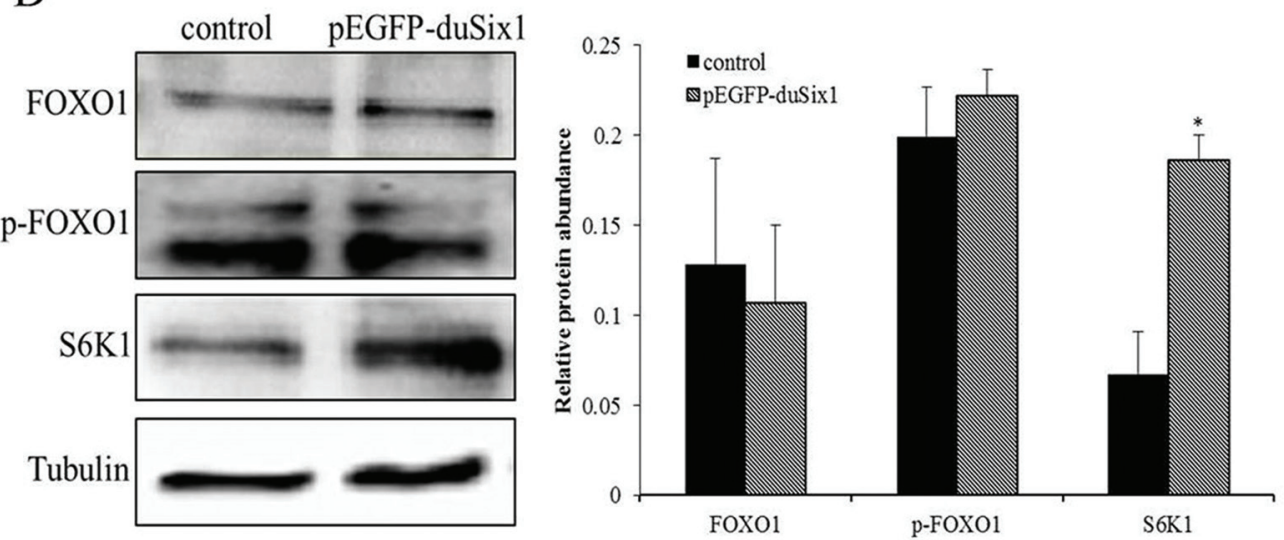

Figure 1 - Effects of overexpression of Six 1 on protein synthesis and degradation in duck myoblasts. A: The expression of GFP in duck myoblasts after transfection of Sixl (100). Notes: (a), (b) and (c) are pEGFP-duSix 1-transfected myoblasts and (d), (e) and (f) are non-transfected myoblasts (control). (a) and (d) showed the shape of the myoblasts in the Cy3 channel; (b) and (e) showed the green fluorescent protein in the FITC channel; (c) and (f) show the overlap of (a) with (b) and (d) with (e), respectively. B: Effects of Six 1-transfection on the cellular proliferation of duck myoblasts at $12 \mathrm{~h}$ and $24 \mathrm{~h}$ after transfection. Cellular proliferation was measured by colorimetric MTT assay. Absorbance was measured at $570 \mathrm{~nm}$, and data are presented as means \pm SEM, $\mathrm{n}=5$ wells. C: Relative expression levels of Six 1 and the key genes related to protein synthesis and degradation in duck myoblasts after transfection. Duck $\beta$-actin and GAPDH were used as the internal controls. $* *(\mathrm{P}<0.01)$ and $*(\mathrm{P}<0.05)$, values are means $\pm \mathrm{SEM}, \mathrm{n}=3$ for each group. $\mathrm{D}$ : Western blot analysis showing the effect of Six 1-transfected on protein expression of FOXO1, p-FOXO1, S6K1 in duck myoblasts. Bar graphs showing quantification of the expression level of each protein compared with the expression of tubulin. Data are expressed as means \pm SEM. Western blots are representative of three independent experiments. Western immunoblots probed with antibodies against FOXO1, phospho-FOXO1, S6K1 and tubulin were used as internal controls. 
A

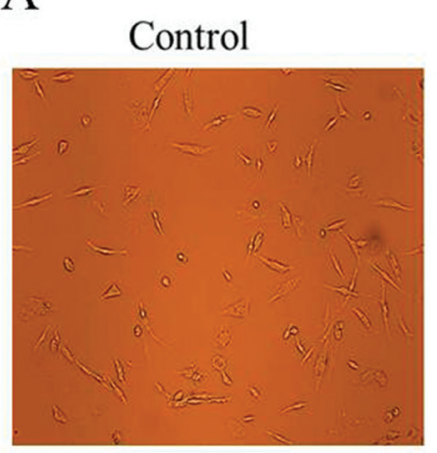

B

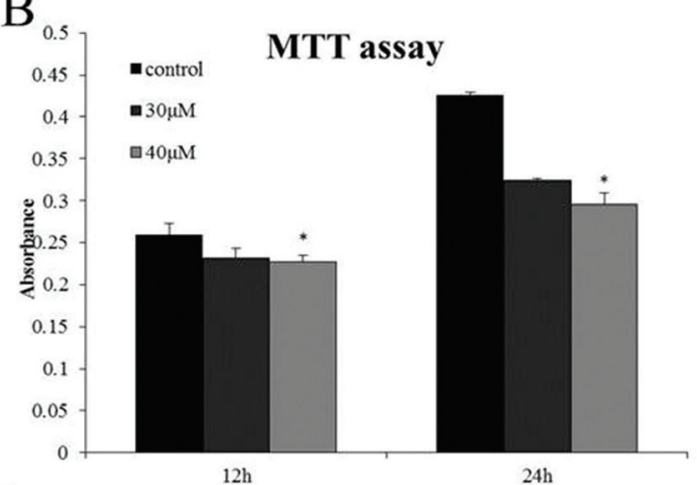

C

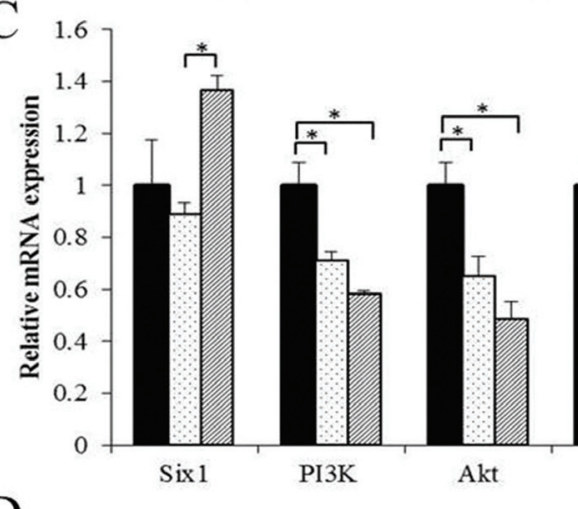

LY294002
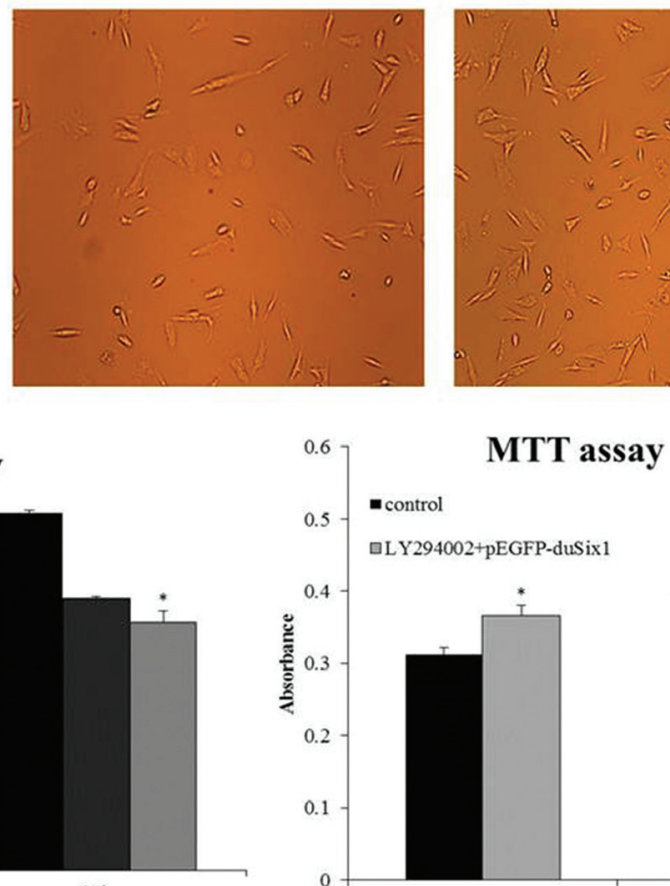

$24 \mathrm{~h}$

LY294002+ pEGFP-duSix 1

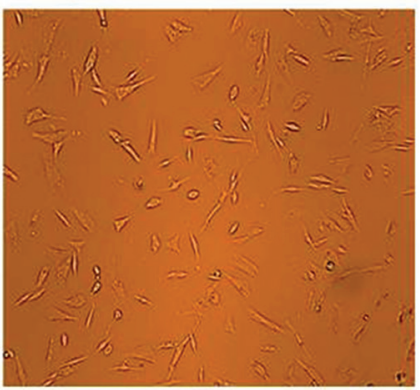

MTT assay

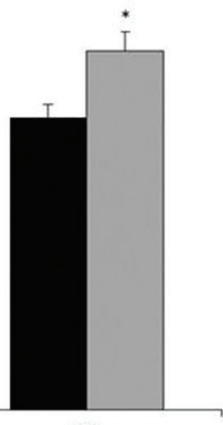

48h

$\mathrm{D}$
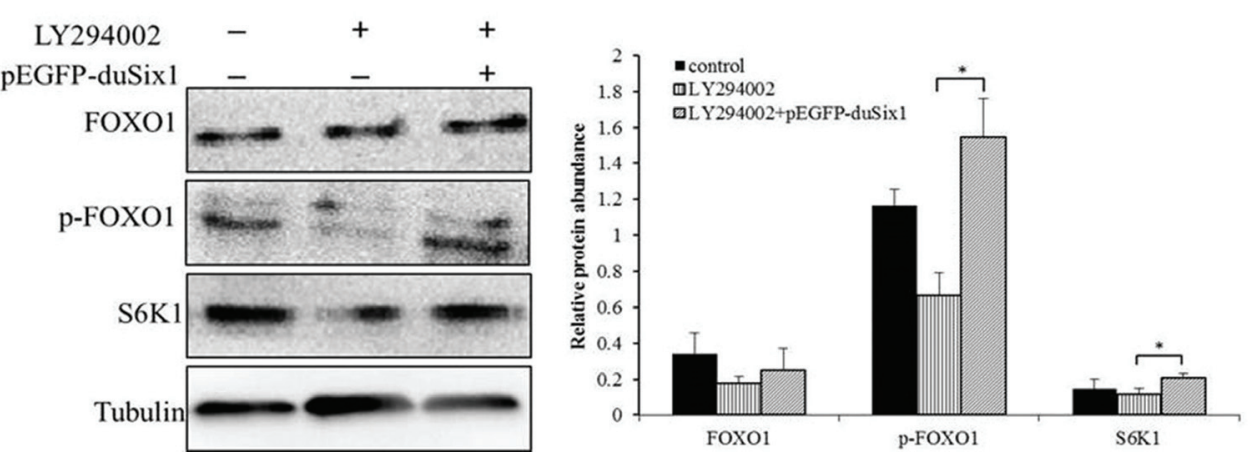

Figure 2 - Overexpression of Six 1 can stimulate protein synthesis in LY294002-treated duck myoblasts. A: Representative images of myoblasts for different treatments groups, (a) control cells, (b) LY294002 treatment cells at $24 \mathrm{~h}$, (b) LY294002 treatment cells for 24 h and then transfected with pEGFP-duSix 1 for $48 \mathrm{~h}$. B: Effects of different treatments on cell proliferation of duck myoblasts at different times. Cell proliferation was measured by MTT assay. Absorbance was measured at $570 \mathrm{~nm}$, and data are presented as means \pm SEM, $\mathrm{n}=5$ wells, $*(\mathrm{P}<0.01)$. C: Relative expression levels of Six 1 and key genes related to protein synthesis and degradation in duck myoblasts of different treatments. Duck $\beta$-actin and $G A P D H$ were used as internal controls. $* *(\mathrm{P}<0.01)$ and $*(\mathrm{P}<0.05)$, values are means $\pm \mathrm{SD}, \mathrm{n}=3$ for each group. D: Western blot analysis showing the effects of transfection of Six 1 on LY294002 treatments in duck myoblasts. Bar graphs showing quantification of the expression level of each protein compared with the expression of tubulin. Data are expressed as means \pm SEM. Western blots are representative of three independent experiments. Western immunoblots probed with antibodies against FOXO1, phospho-FOXO1, S6K1 and tubulin were used as internal controls. 
significantly changed, while $m T O R$ and its downstream $S 6 K 1$ were increased significantly. Previous studies had revealed that Six 1 and its cofactor Eya2 could simulate heart hypertrophy through directly up-regulating $m T O R$ (Lee $e t$ al., 2012). Therefore, to clarify whether overexpression of Sixl simulates myoblasts protein synthesis via $m T O R$, cells were treated with rapamycin (the mTOR inhibitor) at different times and concentrations, as described above. As shown in Figure 3B, the results of the MTT assay indicated that cell proliferation activity was significantly decreased in the presence of this inhibitor, and that inhibition was more serious with prolonged treatment time, but not with the higher concentration of rapamycin. However, after transfecting the rapamycin-treated cells with pEGFPduSix 1 the cell proliferative activity was significantly increased $(\mathrm{P}<0.05)$.

To validate whether overexpression of Six 1 greatly increases $m T O R$ expression in the presence of $30 \mathrm{nM}$ rapamycin and ultimately restores protein synthesis of myoblasts, the same detection methods were performed in this study. Similar to the previous results, real-time PCR showed that relative expression of $m T O R$ was significantly decreased after rapamycin treatment and the same trends were also found in other genes (Figure 3C), indicating that rapamycin could significantly inhibit the activation of mTOR, and finally led to weaken the protein synthesis in myoblasts. In addition, as shown in Figure 3C, overexpression of Sixl could significantly up-regulate the expression levels of $m T O R$ and its downstream effector $S 6 K 1$. However, inconsistent with the previous experiment was the finding that relative expression levels of PI3K, Akt were increased significantly compared with rapamycin treatment. Moreover, expression levels of FOXO1, MuRF1, which is involved in protein degradation, showed insignificant changes after transfection with pEGFP-duSix1. These results provide the evidence that overexpression of Sixl can significantly improve protein synthesis, mainly due to activation of $m T O R$ signaling.

At the protein level, after treating myoblast cells with rapamycin, insignificant changes were found in protein expression of FOXO1, p-FOXO1 and S6K1 (P > 0.05) (Figure 3D), indicating that protein synthesis was inhibited by rapamycin. In addition, the effects of overexpression of Sixl on the rapamycin-treated myoblasts were also investigated, and a significant increase in protein expression of $\mathrm{S} 6 \mathrm{~K} 1(\mathrm{P}<0.05)$ was seen. Moreover, as activation of S6K1 is directly mediated by mTOR, these results indicate that overexpression of Six 1 might promote protein synthesis by inducing the activation of mTOR to directly affect the translation machinery.

\section{Discussion}

\section{Six1 stimulates protein synthesis via $\mathrm{PI} 3 \mathrm{~K} / \mathrm{Akt} / \mathrm{mTOR}$ signaling pathway}

Six 1 was initially considered as a critical transcription factor involved in the formation of eyes and other tissues. Furthermore, numerous studies have pointed out that Sixl is an important regulator required for muscle development (Fougerousse et al., 2002; Laclef et al., 2003: Grifone et al., 2005), muscle fiber differentiation (Grifone et al., 2004), and tumorigenesis (Yu et al., 2006; Farabaugh et al., 2012). Additionally, another study indicated that Sixl is also related to heart muscle hypertrophy (Lee et al., 2012). To further understand the role of Six 1 on PI3K/Akt/mTOR signaling pathway in myoblasts, Six 1 was overexpressed by transfecting duck myoblasts with the eukaryotic expression vector pEGFP-duSix1. Similar to previous research, overexpression of Six 1 could significantly increase protein synthesis by up-regulating the mRNA expression of key genes involved in protein synthesis. Especially, overexpression of Sixl resulted in an obvious increase in the mRNA expression levels of $m T O R$ and both mRNA and protein levels of its downstream $S 6 K 1$. However, the expression levels of muscle atrophy-related signaling genes were not significantly inhibited after transfection for $24 \mathrm{~h}$.

Previous studies have shown that the mRNA expression levels of $M A F b x$ and $M u R F 1$ were increased in atrophic skeletal muscle (Lecker et al., 2004), but were inhibited by the activation of Akt/mTOR signaling in vivo (Bodine et al., 2001). However, Leger et al. (2006) have reported that the mRNA and protein levels of MAFbx and MuRF1 were increased in hypertrophied muscle after 8 weeks of hypertrophy-inducing resistance training. Similarly, running for $30 \mathrm{~min}$ at a moderate-high intensity of $75 \%$ of $\mathrm{V}_{\text {O2max }}$ resulted in an increase in both MAFbx and $M u R F 1$ mRNA expression after 1-4 h of exercise (Louis et $a l ., 2007)$. Therefore, these studies suggested that the regulation of $M A F b x$ and $M u R F 1$ may depend on the manner and intensity of exercise. Our results showed that overexpression of Sixl did not significantly change FOXO1, $M A F b x$ and $M u R F 1$ mRNA expression, and one possible explanation might be the short time of transfection and the transfection efficiency. An alternative explanation could be that overexpression of Six 1 can affect the cell cycle (Ford et al., 2000), the regulation of which is also implicated in the activation of E3 ubiquitin-protein ligase.

\section{Overexpression of Six 1 in myoblasts promotes protein synthesis mainly via activation of mTOR}

As stated above, overexpression of Six 1 could significantly promote cell protein synthesis through up-regulating expression of key genes related to protein synthesis. Moreover, PI3K, as an upstream regulator of this signaling pathway, plays a critical role in protein synthesis and can promote muscle hypertrophy. To further uncover whether 
A
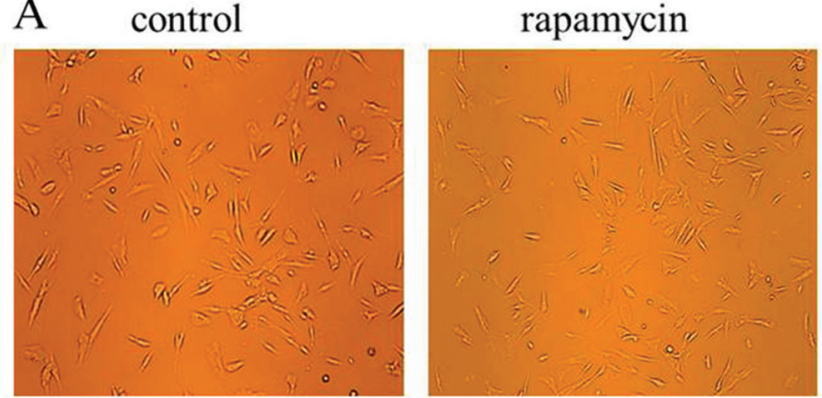

B

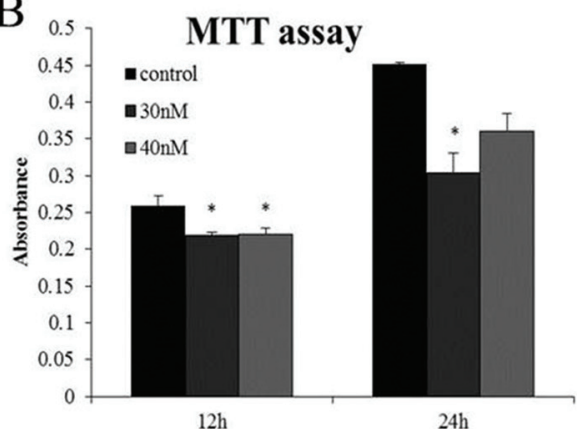

$12 \mathrm{~h}$

C

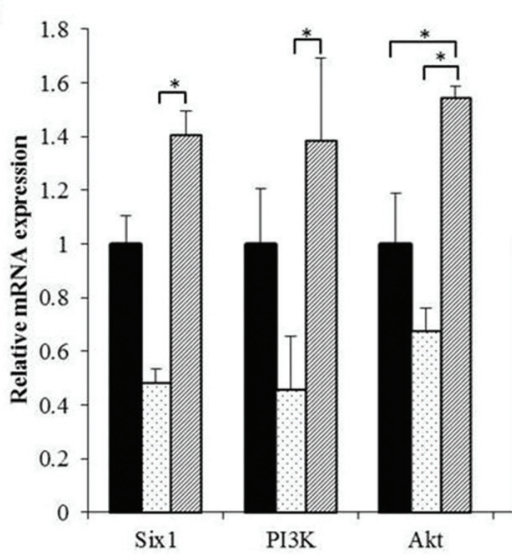

D

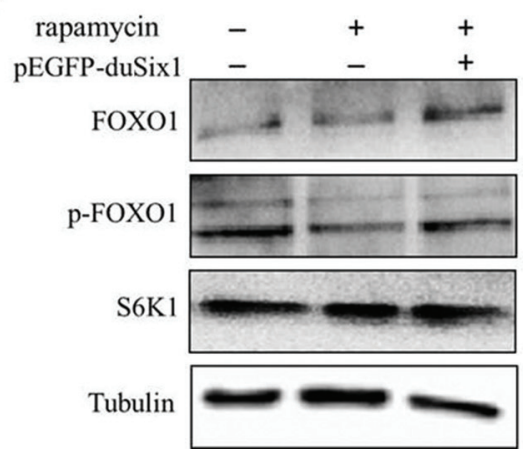

mTOR

S6K

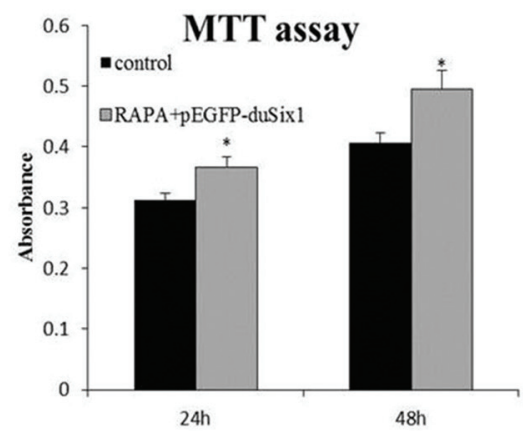

control

口rapamycin

rapamycin+pEGFP-duSix 1

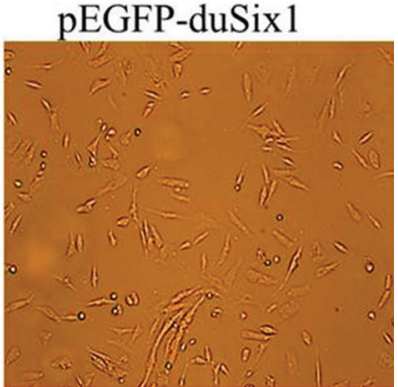

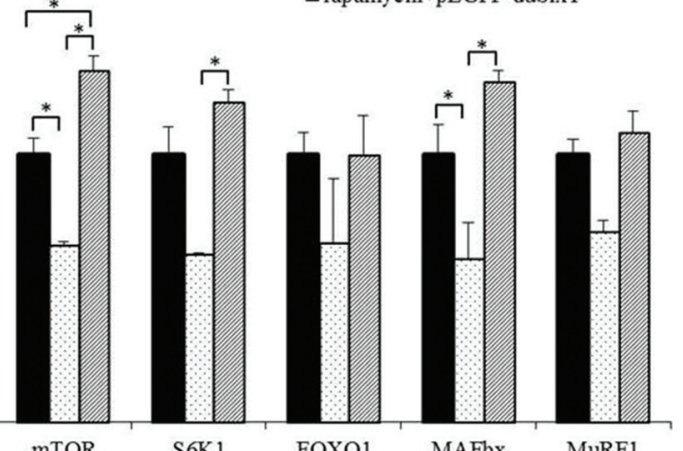

FOXO1

$\mathrm{MAFbx}$

MuRF1

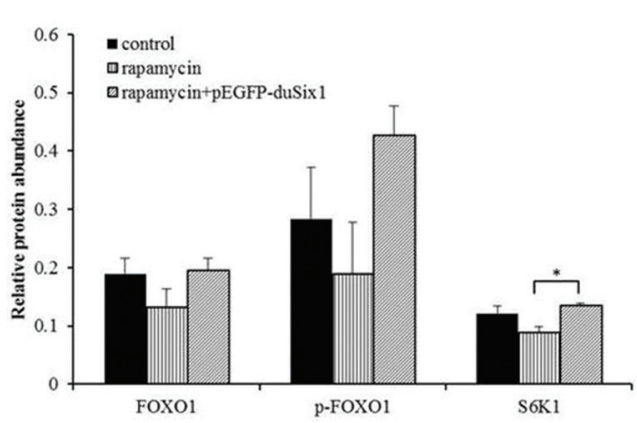

Figure 3 - Overexpression of Six 1 can stimulate protein synthesis in rapamycin-treated duck myoblasts. A: Representative images of myoblasts for different treatments groups, (a) control cells, (b) rapamycin treatment cells at $24 \mathrm{~h}$, (c) Rapamycin treatment of cells for $24 \mathrm{~h}$ was followed by transfection with pEGFP-duSix 1 for $48 \mathrm{~h}$. B: Effects of different treatments on cell proliferation of duck myoblasts at different times. Cell proliferation was measured by MTT assay. Absorbance was measured at $570 \mathrm{~nm}$, and data are presented as means $\pm \mathrm{SEM}, \mathrm{n}=5$ wells, $*(\mathrm{P}<0.01)$. C: Relative expression levels of Six 1 and key genes related to protein synthesis and degradation in duck myoblasts after different treatments. Duck $\beta$-actin and $G A P D H$ were used as the internal controls. ** $(\mathrm{P}<0.01)$ and $*(\mathrm{P}<0.05)$, values are means $\pm \mathrm{SEM}, \mathrm{n}=3$ for each group. $\mathrm{D}$ : Western blot analysis showing the effects of transfection of Six 1 on rapamycin treatments in duck myoblasts. Bar graphs showing quantification of the expression level of each protein compared with the expression of tubulin. Data are expressed as means \pm SEM. Western blots are representative of three independent experiments. Western immunoblots probed with antibodies against FOXO1, phospho-FOXO1, S6K1 and tubulin were used as internal controls. 
PI3K is involved in Six l-mediated regulation of muscular protein metabolism, LY294002, a specific inhibitor of the PI3K/Akt signaling targeting the catalytic site of p110 of PI3K (Liu et al., 2008), was used in this study. It is well known that LY294002 can inhibit the activation of PI3K and ultimately regulate cell proliferation and cell cycle in a variety of cells, such as neutrophils, endothelial cells, and breast cancer cells (Dufourny et al., 1997; Kanda et al., 1997; Pellegatta et al., 1998). Likewise, our results showed that LY294002 cannot only significantly decrease cell proliferation, but also significantly inhibit cellular protein biosynthesis by down-regulating the expression of genes involving the PI3K/AKT signaling pathway. Nevertheless, the results showed that the ubiquitin-proteasome pathway was not obviously up-regulated, showing only an insignificant fluctuation in mRNA levels and FOXO1 protein phosphorylation. Akt can phosphorylate FOXOs and subsequently promote the shift of FOXOs from the nucleus to the cytoplasm. However, phosphorylation of Akt can be blocked by LY294002, then resulting in diminished levels of phosphorylated FOXOs in the cytoplasm and a marked increase in nuclear FOXO proteins, which finally leads to protein degradation via activation of ubiquitin-related signaling. Besides the signaling pathway of protein metabolism, there is still evidence that nutritional support also plays an important role in regulating protein synthesis, as protein degradation may be reduced following gradual consumption of the nutrient substances of cell-culture medium in order to maintain the balance of the cellular protein metabolism (Sakurai et al., 1995). Moreover, the short duration of LY294002 treatment may also be a cause for the unchanged expression of protein degradation signaling pathway.

The effects of rapamycin on cellular protein metabolism were also investigated in duck myoblasts. Rapamycin is a selectively inhibitor of mTOR, as it can bind to members of the FK binding protein (FKBP) family, and the complex rapamycin/FKBP can then bind to mTOR and finally block its activity (Fang et al., 2001; Foster, 2007). A similar result was found as previously described, where rapamycin could significantly decrease cell proliferation and activate mTOR/S6K1 signaling, which plays a critical role in protein synthesis. Previous studies revealed that rapamycin functions by mainly inhibiting the $\mathrm{mTORC} 1$ (one complex of mTOR), but long-term rapamycin treatment in vitro can also inhibit the mTORC2 complex and potentially affect Akt signaling by inducing the expression of $A k t$ (Sarbassov et al., 2006). Furthermore, the mTORC1 complex negatively regulates the IGFI pathway via S6K1 (Um et al., 2004; Aguilar et al., 2007). Interestingly, we found that expression of $P I 3 K$ also decreased after treatment of rapamycin. Similarly, intermittent swimming training and injection with rapamycin in mice for two weeks led to a significant inhibition of PI3K, which may be mediated by a feedback regulation though mTOR/S6K1. Accord- ingly, the decreased mRNA levels of key genes related to cellular protein degradation might be due to reduced nutrient availability and/or the duration of rapamycin treatment.

In the present study, our data indicate that transfection with pEGFP-duSix 1 would arrest the activity of $\mathrm{PI} 3 \mathrm{~K} / \mathrm{Akt} / \mathrm{mTOR}$ signaling pathway, thus attenuating the inhibitory effects of LY294002 and/or rapamycin in duck myoblasts. Interestingly, it was predicted that the promoter region of PI3K (p110 $\alpha$ ) contains putative Sixl binding sites, suggesting that Six 1 may play a regulatory role on $P I 3 K$. However, we found that transfecting myoblasts with pEGFP-duSix 1 in combination with LY294002 treatment did not change the expression of PI3K and Akt. Furthermore, the PI3K/Akt pathway is mainly negatively regulated by many other anti-oncogenes, such as PTEN (Choi et al., 2002), CTMP (Maira et al., 2001) and PHLPP (Gao et al., 2005), to inhibit tumor cell proliferation. These findings indicate that Six 1 may not directly regulate the expression of $P I 3 K$, and insignificant changes in PI3K and $A k t$ expression may result from the effect of other regulator(s). It has been demonstrated that Six 1 and its cofactor Eya 2 could directly up-regulate $m T O R$ (Lee et al., 2012), which is consistent with our results where the expression of $m T O R$ and $S 6 K 1$ were markedly enhanced after transfection. However, transfecting myoblasts with pEGFP-duSix 1 in the presence of rapamycin led to increased expression levels of key genes associated with protein synthesis, which supports the hypothesis that Six 1 can regulate protein synthesis via activation of mTOR. Additionally, the expression of key genes associated with protein breakdown showed an increasing tendency. FOXO1 is regarded as an atrophy gene and acts as a sensor to induce muscle atrophy (McLoughlin et al., 2009). The increasing expression level of FOXO1 protein indicated that, after transfection with pEGFP-duSix1, cellular protein degradation was also increased. The different mRNA expression levels of FOXO1, MAFbx and MuRF1 may, however, be due to the different inhibitor treatment, and more in-depth analyses are needed to address this issue.

In conclusion, the results of this present study showed that overexpression of duck Six 1 can increase protein synthesis, possibly by stimulating muscle hypertrophy-related signaling molecules, while the mRNA levels of key genes related to protein breakdown showed a small but not significant increase after transfection. Furthermore, we treated duck myoblasts with LY294002 and rapamycin (the specific inhibitor of PI3K and mTOR, respectively), and found that these inhibitors can significantly inhibit cellular protein synthesis. Overexpression of duck Sixl could thus ameliorate the inhibitive effects, and Six 1 may up-regulate the expression of $m T O R$ but not $P I 3 K$ to promote protein synthesis. Nonethless, more in-depth research is needed to test this supposition. Taken together, it can be concluded that Six 1 can be regarded as a critical candidate gene to immediately regulate protein synthesis and is important for muscle hypertrophy in avian species. 


\section{Acknowledgments}

The work was supported by the National High Technology Research and Development Program of China (No.2010AA10A109), the National Waterfowl Industrial Technology System (No.CARS-43-6) and Breeding of Multiple Crossbreeding System in waterfowl (2011NZ0099-8).

\section{References}

Aguilar V, Alliouachene S, Sotiropoulos A, Sobering A, Athea Y, Djouadi F, Miraux S, Thiaudiere E, Foretz M, Viollet B, et al. (2007) S6 kinase deletion suppresses muscle growth adaptations to nutrient availability by activating AMP kinase. Cell Metab 5:476-487.

Bernardo BC, Weeks KL, Pretorius L and McMullen JR (2010) Molecular distinction between physiological and pathological cardiac hypertrophy: experimental findings and therapeutic strategies. Pharmacol Ther 128:191-227.

Bodine SC, Stitt TN, Gonzalez M, Kline WO, Stover GL, Bauerlein R, Zlotchenko E, Scrimgeour A, Lawrence JC, Glass DJ and Yancopoulos GD (2001) Akt/mTOR pathway is a crucial regulator of skeletal muscle hypertrophy and can prevent muscle atrophy in vivo. Nat Cell. Biol 3:1014-1019.

Brodbeck S and Englert C (2004) Genetic determination of nephrogenesis: the Pax/Eya/Six gene network. Pediatr Nephrol 19:249-255.

Brugmann SA, Pandur PD, Kenyon KL, Pignoni F and Moody SA (2004) Six 1 promotes a placodal fate within the lateral neurogenic ectoderm by functioning as both a transcriptional activator and repressor. Development 131:5871-5881.

Choi Y, Zhang J, Murga C, Yu H, Koller E, Monia BP, Gutkind JS and Li W (2002) PTEN, but not SHIP and SHIP2, suppresses the PI3K/Akt pathway and induces growth inhibition and apoptosis of myeloma cells. Oncogene 21:52895300 .

Dorn 2nd GW (2007) The fuzzy logic of physiological cardiac hypertrophy. Hypertension 49:962-970.

Dorn 2nd GW and Force T (2005) Protein kinase cascades in the regulation of cardiac hypertrophy. $\mathrm{J}$ Clin Invest 115:527-537.

Dufourny B, Alblas J, van Teeffelen HA, van Schaik FM, van der Burg B, Steenbergh pH and Sussenbach JS (1997) Mitogenic signaling of insulin-like growth factor I in MCF-7 human breast cancer cells requires phosphatidylinositol 3-kinase and is independent of mitogen-activated protein kinase. J Biol Chem 272:31163-31171.

Fang Y, Vilella-Bach M, Bachmann R, Flanigan A and Chen J (2001) Phosphatidic acid-mediated mitogenic activation of mTOR signaling. Science 294:1942-1945.

Farabaugh SM, Micalizzi DS, Jedlicka P, Zhao R and Ford HL (2012) Eya2 is required to mediate the pro-metastatic functions of Six1 via the induction of TGF-beta signaling, epithelial-mesenchymal transition, and cancer stem cell properties. Oncogene 31:552-562.

Ford HL, Landesman-Bollag E, Dacwag CS, Stukenberg PT, Pardee AB and Seldin DC (2000) Cell cycle-regulated phosphorylation of the human SIX1 homeodomain protein. J Biol Chem 275:22245-22254.
Foster DA (2007) Regulation of mTOR by phosphatidic acid? Cancer Res 67:1-4.

Fougerousse F, Durand M, Lopez S, Suel L, Demignon J, Thornton C, Ozaki H, Kawakami K, Barbet P, Beckmann JS and Maire P (2002) Six and Eya expression during human somitogenesis and MyoD gene family activation. J Muscle Res Cell Motil 23:255-264.

Gao T, Furnari F and Newton AC (2005) PHLPP: a phosphatase that directly dephosphorylates Akt, promotes apoptosis, and suppresses tumor growth. Mol Cell 18:13-24.

Giordani J, Bajard L, Demignon J, Daubas P, Buckingham M and Maire P (2007) Six proteins regulate the activation of Myf5 expression in embryonic mouse limbs. Proc Natl Acad Sci U S A 104:11310-11315.

Glass DJ (2005) Skeletal muscle hypertrophy and atrophy signaling pathways. Int J Biochem Cell Biol 37:1974-1984.

Grifone R, Demignon J, Houbron C, Souil E, Niro C, Seller MJ, Hamard G and Maire P (2005) Six 1 and Six 4 homeoproteins are required for $\mathrm{Pax} 3$ and Mrf expression during myogenesis in the mouse embryo. Development 132:2235-2249.

Grifone R, Laclef C, Spitz F, Lopez S, Demignon J, Guidotti JE, Kawakami K, Xu PX, Kelly R, Petrof BJ, et al. (2004) Six1 and Eya1 expression can reprogram adult muscle from the slow-twitch phenotype into the fast-twitch phenotype. Mol Cell Biol 24:6253-6267.

Kanda S, Hodgkin MN, Woodfield RJ, Wakelam MJ, Thomas G and Claesson-Welsh L (1997) Phosphatidylinositol 3'kinase-independent p70 S6 kinase activation by fibroblast growth factor receptor-1 is important for proliferation but not differentiation of endothelial cells. J Biol Chem 272:23347-23353.

Kimball SR (2007) The role of nutrition in stimulating muscle protein accretion at the molecular level. Biochem Soc Trans 35:1298-1301.

Kostek MC, Chen YW, Cuthbertson DJ, Shi R, Fedele MJ, Esser KA and Rennie MJ (2007) Gene expression responses over $24 \mathrm{~h}$ to lengthening and shortening contractions in human muscle: major changes in CSRP3, MUSTN1, SIX1, and FBXO32. Physiol Genomics 31:42-52.

Laclef C, Hamard G, Demignon J, Souil E, Houbron C and Maire P (2003) Altered myogenesis in Six1-deficient mice. Development 130:2239-2252.

Lecker SH, Jagoe RT, Gilbert A, Gomes M, Baracos V, Bailey J, Price SR, Mitch WE and Goldberg AL (2004) Multiple types of skeletal muscle atrophy involve a common program of changes in gene expression. FASEB J 18:39-51.

Lee SH, Kim J, Ryu JY, Lee S, Yang DK, Jeong D, Kim J, Lee SH, Kim JM, Hajjar RJ and Park WJ (2012) Transcription coactivator Eya2 is a critical regulator of physiological hypertrophy. J Mol Cell Cardiol 52:718-726.

Leger B, Cartoni R, Praz M, Lamon S, Deriaz O, Crettenand A, Gobelet C, Rohmer P, Konzelmann M, Luthi F and Russell AP (2006) Akt signalling through GSK-3beta, mTOR and Foxol is involved in human skeletal muscle hypertrophy and atrophy. J Physiol 576:923-933.

Liu P, Xu B, Li J and Lu H (2008) LY294002 inhibits leukemia cell invasion and migration through early growth response gene 1 induction independent of phosphatidylinositol 3kinase-Akt pathway. Biochem Biophys Res Commun 377:187-190. 
Louis E, Raue U, Yang Y, Jemiolo B and Trappe S (2007) Time course of proteolytic, cytokine, and myostatin gene expression after acute exercise in human skeletal muscle. J Appl Physiol 103:1744-1751.

Maira SM, Galetic I, Brazil DP, Kaech S, Ingley E, Thelen M and Hemmings BA (2001) Carboxyl-terminal modulator protein (CTMP), a negative regulator of PKB/Akt and v-Akt at the plasma membrane. Science 294:374-380.

McCarthy JJ, Mula J, Miyazaki M, Erfani R, Garrison K, Farooqui AB, Srikuea R, Lawson BA, Grimes B, Keller C, et al. (2011) Effective fiber hypertrophy in satellite cell-depleted skeletal muscle. Development 138:3657-3666.

McLoughlin TJ, Smith SM, DeLong AD, Wang H, Unterman TG and Esser KA (2009) FoxO1 induces apoptosis in skeletal myotubes in a DNA-binding-dependent manner. Am J Physiol Cell Physiol 297:C548-555.

Musaro A, McCullagh K, Paul A, Houghton L, Dobrowolny G, Molinaro M, Barton ER, Sweeney HL and Rosenthal N (2001) Localized Igf-1 transgene expression sustains hypertrophy and regeneration in senescent skeletal muscle. Nat Genet 27:195-200.

Pellegatta F, Chierchia SL and Zocchi MR (1998) Functional association of platelet endothelial cell adhesion molecule-1 and phosphoinositide 3-kinase in human neutrophils. J Biol Chem 273:27768-27771.

Sakurai Y, Aarsland A, Herndon DN, Chinkes DL, Pierre E, Nguyen TT, Patterson BW and Wolfe RR (1995) Stimulation of muscle protein synthesis by long-term insulin infusion in severely burned patients. Ann Surg 222:283-294; 294-297.

Sandri M (2008) Signaling in muscle atrophy and hypertrophy. Physiology (Bethesda) 23:160-170.
Sarbassov DD, Ali SM, Sengupta S, Sheen JH, Hsu PP, Bagley AF, Markhard AL and Sabatini DM (2006) Prolonged rapamycin treatment inhibits mTORC2 assembly and Akt/PKB. Mol Cell 22:159-168.

Tipton KD, Elliott TA, Ferrando AA, Aarsland AA and Wolfe RR (2009) Stimulation of muscle anabolism by resistance exercise and ingestion of leucine plus protein. Appl Physiol Nutr Metab 34:151-161.

Um SH, Frigerio F, Watanabe M, Picard F, Joaquin M, Sticker M, Fumagalli S, Allegrini PR, Kozma SC, Auwerx J and Thomas G (2004) Absence of S6K1 protects against ageand diet-induced obesity while enhancing insulin sensitivity. Nature 431:200-205.

Wang H, Jint H, Liu H, Sun L, Li X, Yang C, Zhang R, Li L and Wang J (2014) Molecular cloning and expression pattern of duck Six 1 and its preliminary functional analysis in myoblasts transfected with eukaryotic expression vector. Indian J Biochem Biophys 51:271-281.

Yajima H, Motohashi N, Ono Y, Sato S, Ikeda K, Masuda S, Yada E, Kanesaki H, Miyagoe-Suzuki Y, Takeda S and Kawakami K (2010) Six family genes control the proliferation and differentiation of muscle satellite cells. Exp Cell Res 316:2932-2944.

Yu Y, Davicioni E, Triche TJ and Merlino G (2006) The homeoprotein six 1 transcriptionally activates multiple protumorigenic genes but requires ezrin to promote metastasis. Cancer Res. 66:1982-1989.

\section{Associate Editor: Juan Lucas Argueso Almeida}

License information: This is an open-access article distributed under the terms of the Creative Commons Attribution License (type CC-BY), which permits unrestricted use, distribution and reproduction in any medium, provided the original article is properly cited. 